\title{
Assembling Open Hardware at CERN
}

\author{
Luis Felipe R. Murillo \\ (IFRIS $\left.{ }^{1}, \mathrm{CNAM} / \mathrm{LISE}\right)$
}

\begin{abstract}
Under the rubric of "Open Science," new models of coordination and collaboration have been increasingly taken up by research institutions for the development scientific software and hardware. Yet "open" research instruments have understudied socioeconomic, organizational, and political dynamics, describing distinctive modes of participation in scientific knowledge infrastructures. In this paper, I describe the CERN "Open Hardware" initiative with a focus on the exchange practices and technologies of participation that were mobilized to assemble a critical infrastructure with distributed teams at research centers, companies, and Internet-based projects. Drawing from ethnographic and archival research of collaborative and competitive dynamics around "Open Hardware" at CERN, I examine how "open" scientific tools and infrastructures are designed, disputed, and implemented following Free and Open Source development models. In questioning "openness" both at the level of technical objects and their technical collectives, I examine the usage of Open Hardware for validating and assessing research results as well as rendering scientific projects more permeable to new modes of participation in the making of the "technoscience by other means."
\end{abstract}

Keywords: Open Hardware, Open Science, Free and Open Source technologies, CERN.

\section{Introduction}

"Open Science"2 is one of those nebulous, shifting terrains of debate and dispute.

Depending on how we partition the space of scientific practices, technical objects, supporting

infrastructures, and concepts in the contemporary, different narratives can be offered for why,

1 Post-doctoral researcher of the Institut Francilien Recherche Innovation Société (IFRIS) at the Conservatoire National des Arts et Métiers (CNAM), Laboratoire Interdisciplinaire de Sociologie Économique (LISE/CNRS).

2 "Open Science" has, for example, been defined as an academic movement toward "openness, integrity, and reproducibility of scientific research" "“Center for Open Science", source: https://cos.io/about_mission, accessed on 02/20/2016). New developments toward Open Access, open (research) data, and scientific Free and Open Source software are being proposed as fundamental conditions for open science. There are several definitions in dispute and some of them are as old as the debate of sociology of science in the 1940's on the social and institutional norms of science (Bernal 1939 [1967]; Merton 1942 [1973]). See Fecher and Friesike (2014) as well as Albagli, Maciel and Abdo (2015) for recent discussions on the semantic dispersion of the term across national contexts. 
how, where, and who in "Open Science" projects. Here I will not attempt to disentangle these discursive threads which, covered by an illusory stability of the term itself, constitute rather different epistemic objects, but to offer a partial standpoint based on field research at CERN and active participation in the community for "open hardware" (from hereon "OH") late 2016 until mid-2018.

There are several definitions of "open science" and some of them are as old as the debate of sociology of science of the 1940's on the institutional norms of science. Among CERN Knowledge Transfer (KT) officers, tasked with the mission of finding opportunities for commercialization and application to justify public expenditure on basic science, the question of "open science" does not represent much of a novelty as CERN is considered to be doing "open science" since its foundation (Nilsen and Anelli 2016). In their review of this debate, Fecher and Friesike (2013) describe different "schools of thought" along with divisions that are thematic at best (infrastructural, public, pragmatic, democratic, etc.). What is of particular interest for the discussion I propose here is how problematic these divisions become when we zoom in more closely into everyday technoscientific practices. The CERN OH initiative, as a case in point, cannot be interpreted without collapsing and overlapping categories from different "schools of thought," representing, rather, a complex assemblage of technical objects, expert technologists, tech transfer officers, and company executives in a panoply of material, technical, and regulatory affordances and constraints.

In this emergent context for renewed collaborative work in the technosciences, one of the domains of activity with increasing porosity to public participation is that of "open hardware" instrumentation. Historically, Free and Open Source projects have elicited both strong skepticism and engaged enthusiasm with their potential for scaling up collaborations for design, production, 
and decentralization of scientific tools and infrastructures, but they remain a vast open terrain for STS research in the contemporary (Kelty 2001). Under the rubric of "citizen science," for instance, several community initiatives have promoted an ongoing politicization of scientific projects (Wylie et al. 2014). Kimura and Kinchy (2016) describe key areas of concentration on this debate, covering a recurrent problematization of non/lay-experts and expert divides, community-driven data generation and technoscientific outreach, and (de)legitimization of “organic" community initiatives vis-à-vis policy making instances. For contemporary community-centered projects, $\mathrm{OH}$ instrumentation has become an important addition to activist call for reproducibility, transparency, and accountability in scientific research. Among technologists and scholars, Free and Open Source communities are understood to have an historical affinity and yet an undisciplined relationship with the sciences ${ }^{3}$, eliciting both strong skepticism and engaging enthusiasm with respect to their potential for scaling up collaborations for development of research tools and infrastructures. As open projects have been identified in various transdisciplinary spaces as potentially transformative, they have also more recently embodied the promise of what Madelaine Akrich called "science by other means" (Akrich 2016).

The proposal for Free and Open Source-based research and development emerges out of a series of changes in the dynamics of appropriation and circulation of knowledge production postBayh-Dole Act in the 1980's. New infrastructural and instrumental affordances are directly related to the redistributed capacity of small laboratories and individual teams to produce common research tools and resources through open frameworks and licensing schemes (Delfanti

3 See "Free Software / Free Science" by Christopher Kelty (2001) for the discussion of these relations from an STS perspective; in particular, for the parallels between the early genetics research collaboration around the Drosophila Information System (Kohler 1994) and the moral economy of Free Software development (Kelty 2008). Different approaches to the moral economy of science and technology are fundamental for this debate, but they deserve their own dedicated piece which is beyond the scope of this paper (Daston 1995; Fassin 2009). 
2013; Albagli, Maciel, and Abdo 2015). Emergent modes of collaboration have been identified to displace big science management with highly dispersed research and technical staff teams, working across continents with overlapping affiliations and through international scientific consortia, mediating transnational companies, heterogeneous regulatory frameworks, and multilateral cooperation agreements (Gibbons 1994; Mirowski and Horn 2005; Hackett et al. 2005). In tandem with concurrent processes of scientific internationalization, it has been established in the recent STS literature that the so-called "globalization of science" cannot be satisfactorily explained by existing macroeconomic studies of global circulation (Dubois, Gingras and Rosenthal 2016; Maisonobe 2016). A more fruitful theoretical and methodological framing is that of technoscientific assemblages for multi-sited ethnographic studies of the production and circulation of technologies and technologists (Marcus 1995; Fortun and Bernstein 1998; Ong and Collier 2008).

Open scientific hardware is produced at the encounter of specific technopolitical genealogies to engender new forms of engagement. As exemplified by the integration of Free and Open Source-based tools, infrastructures, and development methodologies in contemporary scientific workflows, it is well exemplified in manifestations against intellectual property "maximalism" to be found in various disciplinary contexts. These modes of critique, however, do not resemble those running "out of steam" in the social sciences, pace Latour, but rather the mode of a technical "infrapolitics" that is pragmatically implicated in the making of the technosciences. "Open Access" initiatives, in this regard, have mobilized a much broader nonacademic audience around questions of corporate control of scientific output, resulting in demands for transparency of experimental processes with publication of raw datasets, source code, and high-resolution graphs in addition to the publication manuscripts for peer-review 
(Willinsky 2006). They have also inspired several initiatives for pirating books and academic articles, going against the IP maximalist grain. In this space of contemporary technopolitical shifts and turns, CERN represents a key site of research given its Open Access, Open Data, and Free and Open Source development projects. In particular, the case of CERN OH is of interest for being the site of a series of experiments for creating "open" protocols, licenses, standards, and technologies of participation in the domain of scientific hardware development.

In what follows I will address the implications of open development practices of research tools and infrastructures to illuminate an under-explored dimension of the project for "access to knowledge," here understood primarily as a rubric for the debate regarding the conditions for participation in the production of technoscientific knowledge. Drawing primarily on the example of CERN, I examine how established institutional actors engage in public, community-based open hardware development and, conversely, how peripheral research organizations, companies, and university laboratories engage in design and development of common scientific instruments. Collaboration, as it is well known in the Free and Open Source literature, is not a point of departure but an aspirational end-goal which is everything but trivial to achieve (Feller, Hissam and Lakhani 2007; Kelty 2008; Leach 2009; Coleman 2010). In order to explore the sociotechnical linkages between rather invisible engineering exchange circuits, I suggest following the developmental history of technical objects ${ }^{4}$ to describe practices within and across

4 The approach I adapted for the study of technoscientific objects draws from various STS sources, including the genealogical descriptions of developmental histories in Gilbert Simondon's Du mode d'existence des objets techniques (1958) and the feminist hermeneutics of Sharon Traweek's Beamtimes and Lifetimes (1988). The latter is particularly relevant to quote verbatim on the topic of the construction of research instruments in the HEP community: "I see detectors," explains Traweek, "as material embodiments of the high energy physics culture. They display the tension inherent in the physicists' different experiences and ideas of time and they also provide a model for the resolution of that tension." (Traweek 1988, p. 158). This point has also been stressed for the studies of sciences and techniques by Dominique Pestre: "l'objet technique constitue souvent le point de départ à partir duquel des pratiques autres se créent" (Pestre 1996, p. 25). Similarly for the purposes of archival research, the work of Hans Rheinberger (1997) is particularly useful in accounting for historical genealogies through material (and virtual) traces instead from a history of ideas. 
large-scale scientific research centers, community projects, and innovation laboratories. This is, if the reader concedes, yet another call for the study of mundane or rather "boring" infrastructural things_-following the proposal put forth by Leigh-Star (1999) for the ethnographic study of infrastructures.

\section{Open projects at CERN}

Started as an institutional campaign in 2011, "Open Hardware" has become a rubric for a mode of coordination, a legal device, a set of technical objects, and a tech transfer strategy at CERN. Its context of invention, however, was formed by a much wider concertation of technologies and technologists to interface expert and lay-expert domains. The Knowledge Transfer group (CERN-KT) has been instrumental in creating institutional conditions to support Free and Open Source-based development. Following CERN IP directive of 2010 in support of "Open Source", CERN-KT's strategy has been broaden to support, in addition to traditional IPbased tech transfer mechanisms, collaborative projects in partnership with a recently-created innovation laboratory, CERN Idea ${ }^{2}$ and various Open Access initiatives, such as the "Sponsoring Consortium for Open Access Publishing in Particle Physics” (SCOAP3). Large-scale Open Data projects include, for instance, the data preservation respository "Zenodo," while software tools and platforms encompass research tools such as Geant (simulation software), Zenodo (for longterm preservation of open resources, including papers, data, and software), and ROOT (a framework for storing and analyzing big data). In the space of open hardware, one of the most important initiatives for community-based development has been the funding campaign for

5 Nilsen and Anelli (2016) quote the internal document which reads: "for software developments that are owned in whole or in part by CERN, CERN favors the Open Source approach. Exceptions can be made where there is a good reason not to put the software development under Open Source conditions at a given time" (CERN 2010, emphasis added). 
KiCad, a Free Software CAD program for printed circuit board design. Both CERN staff and sponsored developers have been contributing code and helping to re-organize the KiCad project to welcome new volunteers at various events, including annual, community-based Free Software gatherings. Since its public announcement, CERN has organized "hackathons" for solving bugs and contribute new features to KiCad. Through a donation page hosted at CERN.ch, volunters can directly pay for any number of hours of expert development as a community-led project. In addition to "crowd-funding," the CERN OH initiative has also provided support to the "Icarus Verilog" project, a much-needed piece of software for simulation of code written with the Verilog hardware description language (VHDL). What is particularly important to highlight is not how limited this initiative is to CERN and its specific infrastructural needs, but how these specific needs are points of anchorage for justifying the creation of an ecossytem around $\mathrm{OH}$ projects of much broader scope outside the domain of basic research in particle physics.

Another major contribution from CERN OH initiative has been the creation of an open license meant to cover hardware licensing in a domain of well-guarded restrictions (such as patents and "non-disclosure agreements") of boundary objects, such as hardware, gateware, and software. For the purposes of the CERN OH initiative, existing legal frameworks were examined by CERN-KT experts and a public, an online channel was created to consult on the necessary provisions with hardware practitioners around the Open Source Hardware Association (OSHWA) in the United States. Existing open licenses were studied by the group, and the "Tucson Amateur Packet Radio" (TAPR) was finally adopted as the basis for the "CERN Open Hardware License" (CERN OHL) published in 2011 (Ayass and Serrano 2012). The new hardware license was drafted in collaboration between the engineer Javier Serrano (from the beams control group, CERN BE-CO-HT) and the legal expert Myriam Ayass (from CERN-KT) to provide legal 
conditions for licensees to exercise the right to study, extend, and commercially use digital designs under the condition that new derivative work be distributed with the same licensing terms, basically transposing the key reciprocal obligation of the General Public License (GPL) to the domain of hardware documentation. To include this obligation in their license was a controversial move, but an important one in retrospect: the injunction, which reads for many in the Euro-American Open Source community as "forced reciprocity," was put in place as an incentive for further inclusion of small companies with specialization in scientific instrumentation in collaborative development at CERN. Another important contribution of the CERN OHL was to encode the notion of "documentation" for the broader community, encompassing all the basic elements for replication of a piece of hardware. The OHL, describes the CERN OH group in a co-authored paper, "is more a contract than a license and is built around the idea that whoever takes your design and uses it should agree to not sue you for patent infringement concerning that design. The viral effect of OHL is similar to that of GPL, and this might represent a problem for some companies, so work is ongoing to design a new license that would not have such a strong viral component" (Alvarez et. al. 2009).

Another key technology of participation at CERN is the "Open Hardware Repository," created to facilitate the exchange among hardware desginers at experimental physics facilities, hosting more than one hundred projects with thousands of $\mathrm{OH}$ devices produced and hundreds of institutional end-users (Nilsen and Anelli 2016). Even if the numbers could be deemed irrisory from the perspective of a major research facility, the overall technical and institutional importance of $\mathrm{OH}$ within and beyond $\mathrm{CERN}$ is certainly not. In comparison with broader and

6 The license in its current version (v1.2) reads: ''Documentation' means schematic diagrams, designs, circuit or circuit board layouts, mechanical drawings, flow charts and descriptive text, and other explanatory material that is explicitly stated as being made available under the conditions of this Licence." (CERN OHL 1.2) 
more geographically dispersed software development communities, the CERN OH group is relatively small but extremely influential outside the institution and its partners' networks.

The CERN OHR was launched in 2009 after a manifesto written by the engineer Javier Serrano outling its main purposes as a "place in the web for electronics designers to collaborate on open hardware designs, much in the philosophy of the free software movement."7 The description of its desirable features included the capability of providing electronics design peerreviewing, re-use, and further collaboration with the industry. Having designed the platform in collaboration with a company in the business of "control systems engineering" of former physics researchers, they imagined the space to be the support of an economy of contributions.

Facilitating the interplay between projects, companies, research institutes and engineers, the OHR was modeled to operate as a hub:

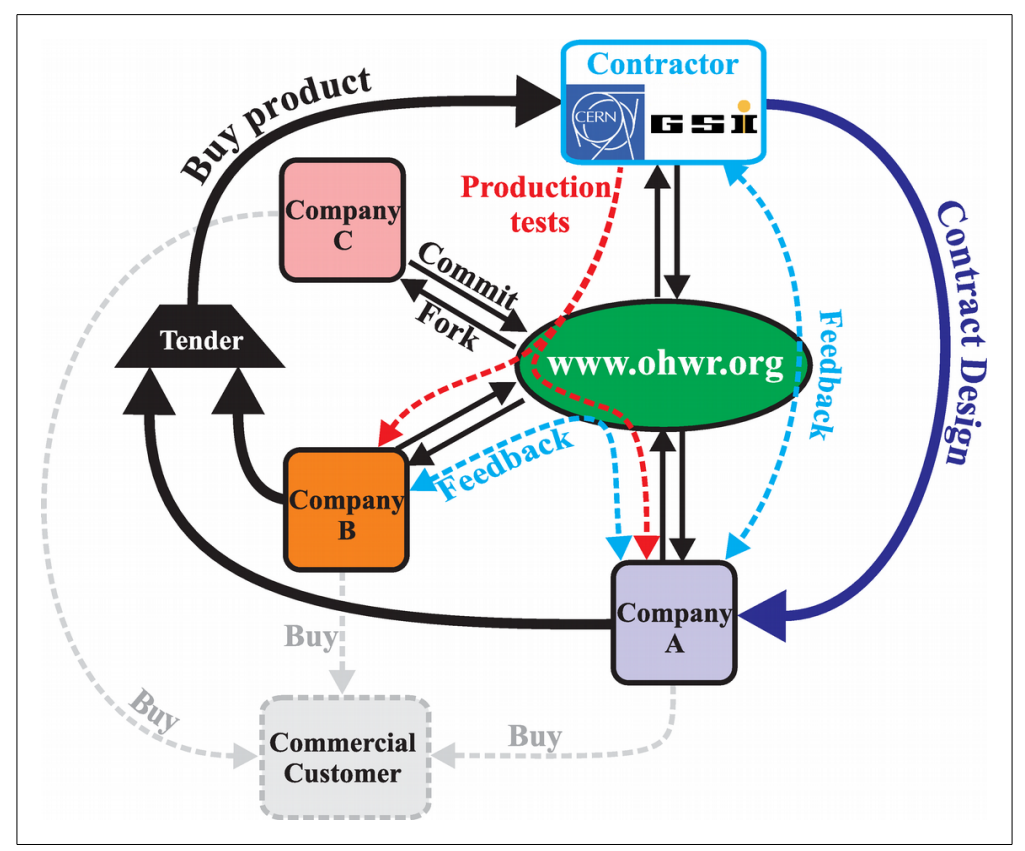

Fig 1. “Open Hardware: How does it work?” by Maciej Lipiński (CERN), 2012

7 Source: https://www.ohwr.org/projects/ohr-support/wiki/manifesto 
Anchored in a legal device, a whole set of contributions and counter-contributions have been made possible. The model describes CERN and GSI as central entities demanding specific types of hardware to be manufactured by a network of partners with the goal of sharing timing and control technologies for particule accelerators (but also for any time-critical network application). From their powerful capacity to act as contractors, CERN and GSI set the conditions for companies to design and manifacture, or just to contribute on CERN-made designs through the mediation of the OHR, which acts as a hub with a pool of designs for re-use, development, modification and redistribution. As the model also preconizes, companies which are not interested in serving CERN or GSI can take a project in another direction (fork), having nothing more of an open hardware license specifying the obligations one has with the original authors; and nothing less than a moral economy constraining free loading and demanding contributions in return (in the form of commits) to the common pool of designs hosted at OHR.org. The model describes the end of the cycle in terms of a return that a manufactured piece of OH hardware to CERN and GSI. As we will see below, the regulation of these forms of exchange have a legal dimension, but they also, and above all, of a moral nature, in the sense that they create obligations for return as a condition for participating in the community as a bona fide member. One of the spokesperson for the $\mathrm{OH}$ initative, Javier Serrano, articulates the problem in these terms: "Free riders are fine. People and companies who take open designs and do not contribute anything back do not pose a problem to us. But what about mean free riders? If somebody takes $\mathrm{OH}$ and uses it to build a closed solution for a profit, that is fine as well, but we would not be clients." (Serrano, Soleil presentation, June 2010). 


\section{Validating reseach results with Open Hardware}

The flagship project of the Open Hardware initiative at CERN is "White Rabbit," an Ethernet-based network technology developed for timing and data synchronization with subnanosecond accuracy and picoseconds precision of synchronization (Bij et al. 2013). In 2006, CERN started to plan for the upgrade of its timing system, Global Machine Timing (GMT), having the GSI Helmholtz Centre for Heavy Ion Research (GSI-FAIR) in Germany as a partner for the design and implementation to address problems of network speed, syncronization, and maintenance. As described in a technical paper by the Serrano et al. (2009), the White Rabbit (WR) project was bootstrapped from the combination (and subsequent extension) of two existing standards, Synchronous Ethernet (SyncE) and PTP (IEEE1588), to create determinist networks for particle accelerators.

In 2010 Serrano was appointed to facilitate the work of two teams for the LHC control infrastructure at the "hardware and timing" section of CERN beams control group (CERN BECO-HT), respectively the hardware design (responsible for custom electronics modules) and the software development teams (writing Linux device drivers for their customized hardware). From this experience, he realized the need for a similar collaborative space for hardware development his other colleagues had in the context of the Linux project. As far as its origin myth goes, one day Javier sat with a copy of the network standard "Precision Time Protocol, version 2" (IEEE1588-2008) and, from all the modifications he made, White Rabbit was first instantiated as an abstract technical object. When reporting about the experience of interaction with the Linux project to merge their code for official distribution, CERN engineers describe the lessons they learned: "it is hard, the Linux Kernel mailing-list and maintainers are tough; one must be prepared to compromise (design, APIs, tools), one must build reputation slowly; requires 
patience." In addition to the technical benefits of merging their contributions with the official Linux source tree, they also realized the need for "contributing back in return to the many benefits the FOSS community gives us." And concluded with the observation that "the original motivations [for their participation] were more ideological than practical $[\ldots]$ but the most important [lesson learned] was that our initial [original] motivations turned out to be wrong," they were given "much more than [they] thought in the first place" (Cobas et al., "Free and Open Source Software at CERN: integration of drivers in the Linux kernel" at the conference “ICALEPCS 2011”).

By examining one recent controversy regarding neutrino physics, we can situate ourselves for better understanding the relevance of White Rabbit as a technology for reproducibility and validation of research results. In 2009 CERN initiated a collaboration with Gran Sasso laboratory of the Italian Institute for Nuclear Research that involved shooting a neutrino beam over 730km across the crust of the earth - from CERN's Meyrin site all the way to a cave in Gran Sasso, Italy. The goal of the collaboration was to explore the last frontier in neutrino physics: the "oscillation" of neutrinos, first observed in the Superkamiokande detector in 1998, leading to the finding of neutrino mass and a subsequent Nobel prize in physics. The oscillation represented a curious behavior of neutrinos: they seemed to change from one type or "flavor" as they traveled, and this transformation was the very object for the experiments of the CERN Neutrinos to Gran Sasso project.

In September $23^{\text {rd }} 2011$, the OPERA group on the Italian side reported an anomaly on a paper with neutrino velocities which exceed the speed of light. The result was curious enough to initiate a prompt, high-level verification of their physics, but the infrastructural conditions underpinning the anomaly were relegated to the last instance of verification. The director of 
OPERA collaboration was quoted in a talk at CERN, saying: "We want to be helped by the community in understanding our crazy result — because it is crazy." Meanwhile, the experiment was caught in a controversy well beyond the caves of Gran Sasso.

The paper the OPERA collaboration uploaded to ArXiv in September 22nd circulated in physics departments and, eventually, found its way to the desk of eager scientific journalists. A mediatic controversy soon spiralled out of control, and the OPERA experiment was re-run, finding the same result just one month later. A memo from the Italian minister of education and research, Mariastella Gelmini, dated September 23rd, 2011, congratulated the scientists for their "finding:" "surpassing the speed of light," she stated, "was an epochal victory for the scientific research of the whole world." The memo proceeds with a gaffe that was rapidly taken up by online parodies as minister Gelmini described the application of estimated 45 million euros for the construction of a "tunnel" between CERN and Gran Sasso. For humourous effect, an Italian internet user registered on the location sharing web platform "Foursquared" the imaginary "tunnel sotteraneo tra il Cern e Il Gran Sasso." (underground tunnel between CERN and Gran Sasso). Meanwhile, Youtube received its fair share of contributed videos on well-played conspiracy which attributed the deadly earthquake of 2009 in Gran Sasso to the experiments with the neutrino beam. As the controversy unfolded, narratives took unexpected directions - as in the children's “telephone game” (“chinese whispers")_ involving misinformed politicians, activist groups, conspiracy theorists, journalists, skeptical physicists, pressured engineers, physicists daydreaming of a Nobel prize, and Internet pranksters brought together by the rapid flow of misinformation.

The veredict, however, did not take too long to arrive after several publications questioning the result and a dedicated committee mobilized at CERN to verify what happened at 
Gran Sasso. The event was finally wrapped up, outside scientific circuits, with humor. The British Telegraph reports in February 22 $2^{\text {nd }}, 2012$ : "scientists did not break the speed of light, it was a faulty wire." At the time of the report, the director of the OPERA experiment had already made public, before resigning, that the problem resided in their GPS equipment which, at the time, provided wrong timestamps and had a loose fiber optic cable connection with their master clock, making neutrinos appear to be have travelled faster than they actually did. For one thing, says one of the engineers who dealt with the pressure on the CERN side, "they had a timing source that was not disciplined," which is to say it was not controlled for drifting of its oscillator. This problem, luckily, did not affected the results, but the one reported as a "loose fiber," he says, "was much harder to detect." Timing was a key for the execution of the experiment. Since samples had to be timestamped on both sides of the experiment, miscalibration in one of the sides would inevitably compromise the results. From their control center, GSL had a 400m fiber connection going into the cave where the detector was located. "Not having the fiber cable connected all the way," explained the beams control engineer, "would generate a different time constant, as capacitors were charged differently in the process of converting light into current at the network interface."

This controversy created the opportunity to validade White Rabbit as a solid technology in the eyes of the physics community, not only for administrators of research facilities, as it served to validate replicated experimental results. From one rather elementary infrastructural problem, a loose cable, to a more complex timing issue regarding an undisciplined GPS source, the syncronization for all the equipment was compromised, leading to the compromise of the OPERA experiment itself. As the timing infrastructure broke down at Gran Sasso, the CERN OH group found an opportunity to run a "real world test" of their OH-based timing and control 
technology. In a optimistic paper published in September 2012 entitled "Performance results of the first White Rabbit installation for CNGS time transfer," the WR development team describes the installation procedures and tests they performed at Gran Sasso laboratory to solve timing problems - involving the syncronization of clocks between CERN and Gran Sasso. In the conclusion of the paper, the $\mathrm{OH}$ group declare, "the described deployment marks an important milestone in the White Rabbit Project—an proof-of-concept technology becomes a working solution. This solution is about to be commercially available while sustaining its openness (open hardware and open software)." WR was still in its beta stage, it is not considered a "mature" technology, "settings were hand-coded, and not automated as they are now,"and, still, the technology was used as a redundancy link at Gran Sasso to compare and contrast with the faulty system they had at place operating at 1 microsecond of accuracy (which, for the standards of WR "timing freaks" it is considered a not-so-good accuracy when compared to the nanosecond-range WR operates).

In another paper with the description of FPGA cards for accelerator control systems, we find a curious discussion for an ordinary technical document named "Open Hardware considerations." This section describes a list of technical and managerial decisions, including the availability of all files that are necessary for fabricating a particular piece of hardware, arguing for their rationale behind the choice of making White Rabbit an $\mathrm{OH}$ project to be supported, as much as possible, with a Free Software toolchain. With a team of consultants and academics in collaboration, CERN OH engineers went through several versions of the technical specification of the WR protocol before transforming it into a stable platform with its own ecossytem of companies, devices, publications, software, and adoptees. The timing extensions to the PTP version 2 (called WRPTP) for acuracy at sub-nanosecond scale were, after a long process of 
validation with competing commercial alternatives, welcomed by the IEEE committee for inclusion in the new version to be published by 2019. To this date, White Rabbit timing networks have been tested for near-future deployment by various organizations outside CERN, such as the GSI Helmholtz Centre for Heavy Ion Research (FAIR) in Germany, the HiSCORE gamma and cosmic-ray experiment in Russia, the Large High Altitude Air Shower Observatory in Tibet, and potentially many origanizations which have not yet communicated of their tests or deployments to the $\mathrm{OH}$ team at CERN.

\section{Technologies of Participation}

As part of the broader initiative for promoing open scientific hardware, the Open Hardware Repository (CERN OHR) has served primarily as the basis for remote coordination of development work of White Rabbit. But it includes source code management repositories, documentation wikis, issue tracking and dedicated mailing-lists for several other projects. Taken as a whole, the OHR is a combination of services with different participatory affordances which inherit, in the background, community-based Free Software projects (such as "Redmine," for issue tracking; "git" and "subversion" for code versioning; and "sympa" for mailing-lists). While some of the contributions are offered and registered using source code management tools (“distributed concurrent versioning system"), others are spatialized through more conventional modes of coordination and collaboration using mailing-lists, regular face-to-face meetings, regional events, and project management techniques for allocation of tasks in loco.

For the preliminary analysis I report below, I collected descriptive statistics from the WR project, but also included peripheral projects within and outside CERN for comparison, such as the AFM board developed with a partner company for project Sirius, a new synchrotron light 
source research facility being built in Brazil. I collected using "git," a DCVS software that was developed in the context of the Linux project for facilitating collaborative coding. The design of 'git' follows closely the sociotechnical organization of the Linux development team. It was written to facilitate highly-distributed work in parallel through 'branches' in an unlinear fashion, and able to address and incorporate conflicting changes to specific parts of the code base (Chacon and Straub 2011). It also allows for the exercise of control over a particular project through similar ways in which Linux is controlled by core maintainers and an assigned project manager which overlooks all of the contributed work: in this mode of coordination, contributors have unbounded "read" permissions on the repository with the possibility of "cloning" the whole repository locally (with its history of changes included), but they do not possess writing permissions on the "origin," unless they are explicitly granted. The Linux kernel development operates in a similar fashion with the figure of the "core" maintainer for a particular sub-system (since the whole operating system kernel project was designed to be broken down into "contributed modules" which can be added to extend up or shrink down the kernel). Collaborative development efforts are, therefore, subordinated to a "release manager" who merges the changes of all the subsystems. This codified mode of coordination and collaboration has influenced many software development teams, and has inspired the creation of a similar space of exchange for hardware designers in the context of the CERN OH initiative as described above, even though, there are ongoing discussions about the inadequacy of source code management systems for collaboration on hardware design files (which involve CAD files, 3D models, etc.).

To register in the CERN OHR, it is necessary to request direct permission for the manager. After an account is created and validated, one is allow to start a new project or 
contribute to an existing one. There are currently 20 registered companies on the main repository, working over one hundred projects:

\begin{tabular}{|c|c|c|c|c|}
\hline Companies & Country & $\begin{array}{l}\text { Number of } \\
\text { projects }\end{array}$ & $\begin{array}{l}\text { Number of } \\
\text { members }\end{array}$ & $\begin{array}{l}\% \text { of total } \\
\text { CERN OHR } \\
\text { projects }\end{array}$ \\
\hline Cosylab & Slovenia & 4 & 4 & $3.9 \%$ \\
\hline Creotech & Poland & 32 & 13 & $31 \%$ \\
\hline Digicom Electronics & USA & 1 & 0 & $0.9 \%$ \\
\hline ELMA & Switzerland & 1 & 1 & $0.9 \%$ \\
\hline GL-Research & Spain & 3 & 1 & $2.9 \%$ \\
\hline Gnudd & Italy & 18 & 2 & $17.8 \%$ \\
\hline HLP Technologies & France & 1 & 1 & $0.9 \%$ \\
\hline Igalia & Spain & 2 & 3 & $1.9 \%$ \\
\hline INCAA Computers & Netherlands & 6 & 2 & $5.9 \%$ \\
\hline $\begin{array}{l}\text { Institute of Electronic } \\
\text { Systems }\end{array}$ & Poland & 2 & 4 & $1.9 \%$ \\
\hline Integrasys & Spain & 2 & 3 & $1.9 \%$ \\
\hline Janz Tec & Germany & 3 & 0 & $2.97 \%$ \\
\hline KAYA Instruments & Israel & 1 & 1 & $0.9 \%$ \\
\hline MagentaSys & Switzerland & 2 & 0 & $1.9 \%$ \\
\hline Milky Mist & France & 1 & 1 & $0.9 \%$ \\
\hline NetTimeLogic & Switzerland & 2 & 1 & $1.9 \%$ \\
\hline ORSoC & Sweden & 1 & 0 & $0.9 \%$ \\
\hline Seven Solutions & Spain & 17 & 6 & $16.8 \%$ \\
\hline Splendeo Innovación & Spain & 1 & 1 & $0.9 \%$ \\
\hline Sundance Technology & UK & 2 & 2 & $1.9 \%$ \\
\hline
\end{tabular}

Table 1. Companies working with CERN OHR. Source: www.ohwr.org/companies

In order to understand the dynamics of coordination and collaboration through $\mathrm{OH}$ development between CERN and its commercial partners, I sampled the complete set of CERN OHR "git" repositories which include core WR technologies (such as the core "gateware" with 
PTP extension, the WR switch, etc.) and more peripheral projects, such AMC FMC card and "hdlmake" which is a piece of software for generating compiling instructions for HDL code. These repositories contain, respectively, hardware design files, gateware, and auxiliary software tools which are necessary to build the hardware. Despite the effort to create conditions for Free Software-based hardware development at CERN, the main tools for hardware engineering are still proprietary: EDA and FPGA synthesis tools. The argument for maintaining a hybrid mixture of proprietary and open technologies resides in the difficulty of finding professional tools for hardware development and FPGA synthesis which are released as Free Software. Adopting existing Free Software tools would have proven divisive for thecollaboration between hardware engineers, so the most Free Software enthusisasts at CERN refrained from enforcing their use. Interestingly enough, the $\mathrm{OH}$ initiative invested, as mentioned above, on the project of creating a Free Software EDA tool, KiCad, as well as HDL simulation tools with hopes that one day in the future they might be able to switch to a fully "free and open" toolchain.

For each project of the OHR I collected, I analyzed data on their 'history' which is included under each 'git' repository. "Git logs" give access to a wealth of information, such as authors and contributors, time, type, and description of contributions. Other types of information can be inferred from, for example, domain names in email addresses and localization (based on the offset to the time registered in UTC). More general information about the activity on the repository can also be generated, such as how long the repository has been in existence, how active it has been, who has been the most active developer and when, how many lines of code have been contributed (if the contents can be broken down in LOCs), and general characteristics about major milestones in a project based on "tagging" of a particular state of the repository (for instance, having a version of the codebase for public release). For the analysis of CERN OHR 
repositories, I concentrated on four basic categories: number of contributors, number of contributions, organization (and country) plus the percentage of contributions to be found be each organization before detailing more fined-grained information about individual "commits" and the the nature of the commited work.

\begin{tabular}{|c|c|c|c|c|}
\hline $\begin{array}{l}\text { Repositories } \\
\text { (git name) }\end{array}$ & $\begin{array}{l}\text { Number of } \\
\text { contributors }\end{array}$ & $\begin{array}{l}\text { Number of } \\
\text { commits }\end{array}$ & $\begin{array}{l}\text { Organizations } \\
\text { (country code) }\end{array}$ & $\begin{array}{l}\% \text { of total } \\
\text { contributions } \\
\text { (rounded) }\end{array}$ \\
\hline \multirow{5}{*}{$\begin{array}{l}\text { White Rabbit cores } \\
\text { (wr-cores) }\end{array}$} & \multirow[t]{5}{*}{21} & \multirow[t]{5}{*}{1353} & CERN (ch) & $63 \%$ \\
\hline & & & GSI (de) & $26 \%$ \\
\hline & & & Elproma (pl) & $7 \%$ \\
\hline & & & Nikhef (nl) & $3 \%$ \\
\hline & & & UGR (es) & $1 \%$ \\
\hline \multirow{6}{*}{$\begin{array}{l}\text { White Rabbit } \\
\text { software } \\
\text { (wrpc-sw) }\end{array}$} & \multirow[t]{6}{*}{22} & \multirow[t]{6}{*}{1488} & CERN (ch) & $45 \%$ \\
\hline & & & Gnudd (it) & $38 \%$ \\
\hline & & & Elproma $(\mathrm{pl})$ & $6 \%$ \\
\hline & & & GSI (de) & $5 \%$ \\
\hline & & & UGR (es) & $0.3 \%$ \\
\hline & & & Seven Solutions (es) & $0.2 \%$ \\
\hline \multirow{4}{*}{$\begin{array}{l}\text { White Rabbit } \\
\text { network interface } \\
\text { (wr-nic) }\end{array}$} & \multirow[t]{4}{*}{9} & \multirow[t]{4}{*}{124} & Seven Solutions (es) & $38 \%$ \\
\hline & & & CERN (ch) & $22 \%$ \\
\hline & & & Elproma (pl) & $18 \%$ \\
\hline & & & UGR (es) & $22 \%$ \\
\hline \multirow{2}{*}{$\begin{array}{l}\text { White Rabbit } \\
\text { switch gateware } \\
\text { (wr-switch-hdl) }\end{array}$} & \multirow[t]{2}{*}{7} & \multirow[t]{2}{*}{794} & CERN (ch) & $99 \%$ \\
\hline & & & Seven Solutions (es) & $1 \%$ \\
\hline \multirow{2}{*}{$\begin{array}{l}\text { White Rabbit } \\
\text { switch hardware } \\
\text { (wr-switch-hw) }\end{array}$} & \multirow[t]{2}{*}{6} & \multirow[t]{2}{*}{358} & Seven Solutions (es) & $99 \%$ \\
\hline & & & Creotech $(\mathrm{pl})$ & $1 \%$ \\
\hline \multirow{8}{*}{$\begin{array}{l}\text { White Rabbit } \\
\text { switch software } \\
\text { (wr-switch-sw) }\end{array}$} & \multirow[t]{8}{*}{18} & \multirow[t]{8}{*}{2312} & CERN (ch) & $49 \%$ \\
\hline & & & Gnudd (it) & $39 \%$ \\
\hline & & & Seven Solutions (es) & $8 \%$ \\
\hline & & & UGR (es) & $4 \%$ \\
\hline & & & UTwente (nl) & $0.4 \%$ \\
\hline & & & Integrasys (es) & $0.1 \%$ \\
\hline & & & GSI (de) & $0.09 \%$ \\
\hline & & & Jive (eu) & $0.04 \%$ \\
\hline
\end{tabular}




\begin{tabular}{|c|c|c|c|c|}
\hline \multirow{2}{*}{$\begin{array}{l}\text { SVEC board } \\
\text { (svec) }\end{array}$} & \multirow[t]{2}{*}{6} & \multirow[t]{2}{*}{84} & CERN (ch) & $75 \%$ \\
\hline & & & Creotech (pl) & $25 \%$ \\
\hline \multirow{2}{*}{$\begin{array}{l}\text { AMC FMC card } \\
\text { (afc) }\end{array}$} & \multirow[t]{2}{*}{5} & \multirow[t]{2}{*}{44} & Creotech $(\mathrm{pl})$ & $53 \%$ \\
\hline & & & LNLS (br) & $47 \%$ \\
\hline $\begin{array}{l}\text { FMC ADC card } \\
\text { (fmc-adc-130m-16b- } \\
\text { 4cha) }\end{array}$ & 2 & 10 & Creotech (pl) & $100 \%$ \\
\hline
\end{tabular}

Table 2. Contributions to individual repositories at CERN OHR

In terms of preliminary findings, it can be said that projects tend to be very small (around 10 persons per repo) displaying a common distribution of labor in FOSS projects, whereas $20 \%$ tends to do $80 \%$ or more of the work. Most of the work for gateware and hardware design is highly concentrated around CERN and lightly distributed to GSI and other companies, such as Seven Solutions and Elproma, or university partners, such as University of Granada. There are companies working specifically on software (for firmware development, such as Gnudd) whereas other companies are only dedicated to hardware design and manufacturing (such as Creotech and Seven Solutions). From the time of commits, we learn that most of the work is done during regular business hours (9:00 until 17:00 with peak activities around 11:00 and 16:00 respectively). One of the few interesting "forks" so far has been done under contract for project Sirius, the new synchrotron light source built for the Brazilian Synchrotron Light Laboratory (LNLS) by the Polish company Creotech (where the latter is responsible for a bit over half of the work in relation the former).

\section{Discussion}

In his account of the protohistory of CERN, Dominique Pestre (1984) described how a particular kind of openness was one of the determining factor in the creation of an international 
science collaboration in continental Europe after the Second World War. The secrecy surrounding the technoscientific black-boxed instruments of United States was finally put into question when President Truman announced the detonation of the first soviet nuclear bomb in September 23 ${ }^{\text {rd }}$, 1949. Commenting on this particular event, Pestre quotes Lew Kowarsk from the "Committee for Atomic Energy" (CEA) who evaluates: "il est certain qu'il devient de plus en plus difficile de maintenir la fiction d'un important "secret" dans la science et la technologie atomique pré-1948" (Pestre 1984, p. 67). This foundational history is what informs the CERN-KT director and his collegue to cite the CERN convention of 1953 , which posits that "all scientific results shall be made openly available to the public," before they describe various open models of technology transfer they support (Nilsen and Anelli 2016).

In this paper I have described how "openness" is being worked out at the level of technical objects through a specific form of assembly. As open hardware becomes a constitutive part of critical research infrastructures, I have suggested through the example of the application of White Rabbit for the verification of research findings of the "CERN Neutrinos to Gran Sasso" project how knowledge-making and truth claims depend upon the nature of open research instruments; identifying their importance in the dispute to establish scientific facts in the order of scientific knowledge. The history of CNGS' neutrino controversy speaks about ordinary blackboxing and ordinary dispute between research teams for scientific distinction, but it also speaks about a more invisible process due to its infrastructural nature, but without which, no validation and further verification of research results can be performed.

To understanding the specificity of this open infrastructural technology, I examined personal and historical narratives of the event, publications, mediatic controversies and parodies 
to illuminate the ways in which the open infrastructure is made possible through a series of technologies of participation. White Rabbit, as a case in point, is a flagship project for CERN infrastructure, but its broader societal and economic relavance largely surpasses the specificities of large-scale facilities for basic research. It represents a case of "experimental innovation" with unexpected impact on various fields, such as: 1) education and training; 2) business opportunities for SMEs which can rely on a distributed knowledge infrastructure to provide their services; 3 ) animating broader, internationalized science and engineering collaborations for maintaining and expanding research infrastructures; and, last but not least, 4) validating of scientific results.

For further development of the analysis I presented here, I can anticipate here at least two potential directions: first, toward the study of $\mathrm{OH}$ technologists' trajectories to further explore the moral economies which sustain the technoscientific exchange around Free and Open Source technologies. In practical terms, this analytic direction would demand moving past beyond the calm surface of discourses, models, and publications to follow the technical work on the electronics bench as well as in the code repositories through field research. Trajectory analysis, when combined with the study of code repositories and documentary analysis, would yield a much richer understand of development history of technical objects as means for participation. And, second, the extension of the ethnographic field research beyond CERN would be particularly important to shed light on the adoption and adaptive work being perform by companies and research institutes on the open technical objects that are being primarily develop at CERN. As I describe in this paper, there is strong evidence to support that Free and Open Source technologies have become one of the means through which the sciences are rendered more permeable to (public) participation, despite the challenges that it represents. Exploring 
emergent forms of collaborative work - as well as the challenges for engaging collaborative ties across institutions and domains of expertise — will provide the basis for understanding broader transformations under the registers of openness, accessibility, reproducibility, and extensibility of the sciences in the contemporary. Despite some experimental advances, the promises of "Open Science"-in the contemporary sense of the term—-have yet to be realized.

\section{REFERENCES}

Daston, Lorraine. 1995. “The Moral Economy of Science,” In: Osiris: 2-24.

Fortun, M and Bernstein, H.J. 1998. Muddling through: Pursuing science and truths in the 21st Century. Washington, D.C.: Counterpoint.

Ackerman, J. R.. 2008. “Toward Open Source Hardware”. In: University of Dayton Law Review, $34,183$.

Albagli, Sarita; Maria Lucia Maciel and Alexandre H. Abdo. 2015 (ed.). Open Science, open issues. Brasília: IBICT; Rio de Janeiro: Unirio.

Ayass, M. and Serrano, J. 2012. "The CERN Open Hardware Licence" in: International Free and Open Source Software Law Review. Retrieved from: www.ifosslr.org/ifosslr/article/view/65

Bij, E. van der; Arruat, M.; Cattin, M.; Daniluk, G.; Cobas, J. D. G.; Gousiou, E.; Wlostowski, T. (2013). How to create successful Open Hardware projects - About White Rabbits and open fields. In: Journal of Instrumentation, 8(12), C12021.

Delfanti, Alessandro. 2013. Biohackers. The Politics of Open Science. London: Pluto Press.

Edwards, P. N. 2010. A Vast Machine: Computer Models, Climate Data, and the Politics of Global Warming. Cambridge, MA: MIT Press.

Fecher, Benedikt, and Sascha Friesike. 2014. "Open Science, One Term Five Shools of Thought". In: Sönke, Bartling and Sascha Friesike (org.). Opening Science: The Evolving Guide on How the Internet Is Changing Research, Collaboration and Scholarly Publishing. pg.17-47. Cham: Springer International Publishing.

Feller, Joseph, Brian Fitzgerald, Scott A. Hissam, and Karim R. Lakhani. 2007. Perspectives on Free and Open Source Software. Cambridge, MA: MIT Press. 
Galison, Peter and Bruce Hevly. 1992. Big science: The growth of large-scale research. Stanford: Stanford University Press.

Gibbons, Michael. 1994. "Transfer Sciences: Management of Distributed Knowledge Production.” In: Empirica 21 (3): 259-70.

Kelty, Christopher M. 2001. "Free Software/free Science.” in: First Monday 6 (12). http://journals.uic.edu/ojs/index.php/fm/article/view/902.

Press. . 2008. Two Bits : the cultural significance of free software. Durham: Duke University

Kimura, Aya H., and Abby Kinchy. 2016. "Citizen Science: Probing the Virtues and Contexts of Participatory Research.” Engaging Science, Technology, and Society 2 (0): 331-61.

Maisonobe, Marion et al.. 2016. "L'évolution mondiale des réseaux de collaborations scientifiques entre villes : des échelles multiples". In: Revue française de sociologie 2016/3 (Vol. 57), p. 417-441.

Mirowski, Philip, and Robert Van Horn. 2005. "The Contract Research Organization and the Commercialization of Scientific Research.” In: Social Studies of Science 35 (4): 503-48.

Nafus, Dawn. 2012. 'Patches Don't Have Gender': What Is Not Open in Open Source Software.” In: New Media \& Society, 14, no. 4: 669-83.

Nilsen, V., and Anelli, G.. 2016. "Knowledge transfer at CERN". In: Technological Forecasting and Social Change. 112, 113-120.

Pearce, Joshua. 2013. Open-Source Lab: How to Build Your Own Hardware and Reduce Research Costs. Amsterdam; Boston: Elsevier.

Pestre, Dominique. L'organisation européenne pour la recherche nucléaire (CERN) [Un succès politique et scientifique]. In: Vingtième Siècle, revue d'histoire, n , octobre 1984. pp. 65-76.

. 1996. "La reconstruction des sciences physiques en France après la Seconde Guerre

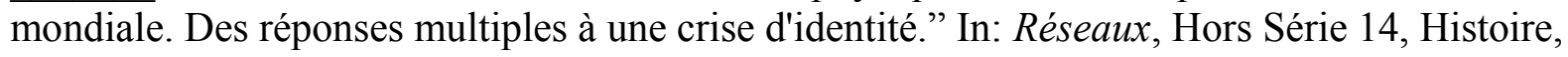
recherche télécommunications. pp. 21-42.

Rheinberger, H-J. 1997. Toward a history of epistemic things: synthesizing proteins in the test tube. Stanford, Calif.: Stanford University Press.

Serrano, Javier, P. Alvarez, M. Cattin, E. G. Cota, P. M. J. H. Lewis, T. Włostowski et al. 2009. "The White Rabbit Project," in: Proceedings of ICALEPCS TUC004, Kobe, Japan. 
Simondon, Gilbert. 1958. Du mode d'existence des objets techniques. Paris: Aubier.

Traweek, Sharon. 1988. Beamtimes and Lifetimes: the world of high energy physicists. Cambridge, Mass.: Harvard University Press.

Willinsky, John. 2006. The Access Principle: The Case for Open Access to Research and Scholarship. Cambridge, Mass.: MIT Press. 